\title{
Measuring Energy Poverty in Japan, 2004-2013
}

\author{
Shinichiro Okushima \\ Graduate School of Systems and Information Engineering, University of Tsukuba, \\ 1-1-1, Ten-nodai, Tsukuba-science-city, Ibaraki, 305-8573, Japan. \\ E-mail: okushima@sk.tsukuba.ac.jp
}

\begin{abstract}
This paper first examines energy (or fuel) poverty in Japan from 2004 to 2013, especially around the time of the 2011 Great East Japan Earthquake (GEJE). To analyze the issue, the paper employs various poverty and vulnerability measures with the assistance of our unique dataset. The results indicate the aggravation of energy poverty among lower-income and vulnerable households during the past decade, resulting from both the escalation of energy prices and lowering of income. The analysis also employs a new decomposition technique and identifies the explanatory factors associated with the increase in energy poverty. These results suggest there were major changes in the forces driving the increase in energy poverty before and after the GEJE. After 2011, income alleviates energy poverty in Japan, with energy prices becoming the main driving factor.
\end{abstract}

Keywords: Decomposition, Energy poverty, Fuel Poverty, Great East Japan Earthquake, Measurement, Vulnerability

JEL: D63, I32, Q49 


\section{Introduction}

Japan faces an unprecedented situation concerning energy policy. After the Great East Japan Earthquake (GEJE) and consequent Fukushima nuclear power plant accident in March 2011, Japan’s nuclear power plants have barely operated over several years, resulting in Japan becoming increasingly dependent on fossil fuel imports, especially liquid natural gas (LNG), for electricity generation, a development coinciding with the significant depreciation of the yen (see, e.g., METI, 2014b, 2015). The Japanese government has sought to promote renewable energy production after the incident at Fukushima, using measures such as a feed-in-tariff (FIT) scheme. Recently, this policy is starting to garner much attention regarding the possibility of a heavy burden on the shoulders of households in the near future (e.g., METI, 2016). ${ }^{1}$

Adding to this movement toward 'denuclearization', the government introduced a new tax on fossil fuels to address climate change, and raised Japan's consumption tax to better sustain the existing social security system. Combined, these developments have significantly increased energy costs in Japan, and, eventually, they will further increase the burden placed on households for energy use, despite recent falls in international energy prices.

\footnotetext{
1 The latest Strategic Energy Plan by the government, approved by the cabinet on April 2014, also expresses concern regarding the possible heavy burden on households in the future, mentioning, 'Renewable energy introduced based on the feed-in-tariff program is expected to increase and may become a cost-increasing factor for electricity users’ (METI, 2014a).
} 
Apart from these problems regarding energy costs, there is a compounding problem. The share of low-income households in Japan is steadily increasing because of population aging and its continuing sluggish economy (see, e.g., MHLW, 2012a, 2012b). Vulnerable households, e.g., single-parent-with-dependent-child(ren), elderly, and single-person households, are much more sensitive to rising living costs, including energy (Boardman, 2010; Hills, 2012). From this point of view, the problem of energy poverty — the theme of this study — could be a worrisome concern for Japan on a middle- to long-term basis. As discussed later, energy poverty means the condition of not being able to meet basic energy needs.

Against this background, this paper provides a historical analysis of the situation of energy poverty in Japan after the 2000s, especially around the time of the GEJE and the Fukushima nuclear power plant accident, and specifies the factors accounting for the increase in energy poverty in Japan in that period. Since there are few studies concerning the matter in Japan, this is the first to show empirically the certainty of energy poverty in Japan after the 2000s, using detailed microdata, particularly among lower-income and vulnerable households. To achieve that end, the paper employs vulnerability and poverty measures, and a new decomposition technique using our unique dataset.

The remainder of the paper is structured as follows. Section 2 discusses the concept of energy poverty. Section 3 explains the data used in the analysis. Section 4 discusses the results. The final section provides some concluding remarks. 


\section{Measuring energy poverty}

Energy (or fuel) poverty, which is the main subject of this analysis, can be defined conceptually as the condition of lacking the resources necessary to meet basic energy needs, following the definition of food poverty given by Greer and Thorbecke (1986). ${ }^{2}$ Bouzarovski et al. (2012) provide a similar definition in which energy poverty describes a condition wherein a household cannot access energy services at the home up to a socially and materially necessitated level. The ways of thinking about energy poverty can be split usually into one of two types. The first is 'availability', concerning the lack of access to modern types of energy (e.g., electricity), which is generally the focal point in a developing country context (e.g., IEA, 2010). The second is ‘affordability’, comprising various issues that prevent people from satisfying their basic energy needs. This is the typical focus of the energy poverty problem in developed countries like Japan. As for income poverty, the issue of energy poverty in developed countries has a 'relative' nature while that in developing countries has an 'absolute' nature (see, e.g., Kakwani and Silber, 2007). Even in developed countries, the problem of energy poverty can be a major social issue that potentially affects millions of

${ }^{2}$ For simplicity, we regard ‘energy poverty’ as synonymous with 'fuel poverty’, although other researchers, e.g., Li et al. (2014), consider that the former has a broader meaning than the latter, and so require a strict distinction between the two terms. In our view, the term 'energy poverty' is more suitable for the context of Japan, as well as Germany, because the problem in both countries is largely affected by higher expenses for electricity (Schuessler, 2014). 
households and individuals, and may account for significant hardships, negative health impacts, and additional carbon emissions (Hills, 2011, 2012).

To date, there has been rather less attention given to the energy poverty problem in developed countries than in developing countries (Boardman, 2010; Bouzarovski et al., 2012; Brunner et al., 2012). However, since Boardman’s (1991) seminal work, the UK context has become the exception. Besides regular annual reports, there have been several reports on the issue of energy poverty by the UK government, among others. Of special note, the Hills fuel poverty review suggested a new approach to evaluating energy poverty (Hills, 2011, 2012). Subsequently, there is a recently growing literature on energy poverty in the UK, such as Boardman (2010), Chawla and Pollitt (2013), Moore (2012), and Waddams Price et al. (2012), on other European Union (EU) countries such as Austria (Brunner et al., 2012), Germany (Heindl and Schuessler, 2015; Schuessler, 2014), and Spain (Phimister et al., 2015), and as a comparative study across the EU (Bouzarovski et al., 2012; Thomson and Snell, 2013).

On poverty measurement, evaluating poverty comprises these two steps (Sen, 1976, 1979). The first step is ‘identification’ — that is, who are the poor? —and the second step is 'aggregation'-how are the poverty characteristics of different people to be combined into an aggregate measure? Identification involves the practical definition of certain given standards — the poverty line — that might separate 'the poor' from 'those that are not poor'.

Setting the poverty line is a troublesome but necessary task. In terms of energy poverty, energy budget shares often serve as standards (see, e.g., Pachauri 
et al., 2004). Boardman (1991)—-the de facto founder of energy poverty measurement—suggested the first quantified definition of energy poverty for the UK: households are in energy poverty when they are unable 'to have adequate energy services for $10 \%$ of income'. The UK government officially uses this approach; one of their poverty measures - the so-called ' $10 \%$ indicator'-defines a household in fuel poverty as one that needs to spend more than $10 \%$ of its income on fuel costs (DECC, 2010). ${ }^{3}$ The fuel costs include energy consumption for space heating, water heating, lights and appliances, and cooking, but exclude the energy for driving cars.

In terms of 'aggregation', this $10 \%$ indicator is a kind of headcount ratio, which identifies the extent of poverty in a society using the proportion of the 'poor' in the total population. The headcount ratio is popular and widely used as an income poverty measure. ${ }^{4}$ We employ a variant of this measure in our analysis for generality and simplicity, as discussed later in detail.

\footnotetext{
3 Along with this definition, the UK government uses an alternative definition being the Low Income High Cost (LIHC) indicator. See, e.g., Hills (2012) for details. The LIHC indicator is nevertheless being criticized by some researchers. For example, Heindl and Schuessler (2015) prove that the LIHC indicator has counter-intuitive dynamic properties, which may cause false policy implications.

4 That said, the headcount ratio has some well-known problems. One is that it pays no attention to the 'depth' of poverty and thus evaluates the marginally poor the same as the miserably poor. These drawbacks also generally apply to the $10 \%$ indicator. For more general information on poverty measures, see Sen (1997) and Haughton and Khandker (2009).
} 
Energy poverty and general income poverty are closely related; hence, researchers have often not treated energy poverty as an independent problem. However, there is good reason to do so. In the field of poverty measurement, there is a broad consensus that deprivation is multidimensional and therefore looking only at income poverty is insufficient (Atkinson, 2003; Bourguignon and Chakravarty, 2003). The concept of energy poverty perceives poverty not just as the lowness of income, but also as the inability to meet some elementary and essential needs (Sen, 1997). ${ }^{5}$ Maintaining an adequate level of warmth at home is a clear example of such basic needs. Many studies empirically show that energy poverty is a distinct problem not subsumed into general income poverty (see, e.g., Pachauri et al., 2004; Hills, 2011, 2012; Phimister et al., 2015). For this reason, Boardman (2010, p. 21) appropriately declares that currently, 'fuel poverty is politically accepted as a real problem’.

\section{Data}

We measure energy poverty in Japan using the unique microdata on household income, expenditure, and characteristics in a sample of about 50,000 households covering all of Japan. The dataset is created by my own work using anonymized information in the 2004 National Survey of Family Income and

\footnotetext{
${ }^{5}$ In the context of 'specific egalitarianism' by Tobin (1970), we need to consider the distribution of 'certain specific scarce commodities' including basic necessities like food, energy, housing, etc., as well as the distribution of income.
} 
Expenditure, provided by the National Statistics Center for this research purpose. ${ }^{6}$ The dataset enables us to perform a complete analysis of energy poverty by focusing on detailed household characteristics.

For the purpose of the analysis, we need to perform two types of modification. The first data modification is seasonal adjustment (see the Appendix for details). As discussed, the anonymized microdata are made from the National Survey of Family Income and Expenditure, with expenditure data collected in autumn (from September to November for two-or-more-person households and from October to November for one-person households). ${ }^{7}$ Energy poverty is a problem aggravated in winter, above all in January, the coldest month in Japan. Hence, we construct seasonally adjusted expenditure data using another government household survey, the Family Income and Expenditure Survey. This survey has a much smaller sample, but the data are monthly, using the same definition. We construct seasonally adjusted data on household expenses for energy goods ('electricity', 'gas', and 'other fuels'), using monthly figures for the same energy goods in the Family Income and Expenditure Survey. In the results, we use the annual average expenditure data, obtained by this procedure, to

\footnotetext{
6 The Statistics Bureau of the Ministry of Internal Affairs and Communications conducts the National Survey of Family Income and Expenditure every five years. The sample size is about 57,000 households, significantly larger than the 9,000 households of the Family Income and Expenditure Survey conducted monthly by the same ministry.

${ }^{7}$ Unlike the expenditure data, income is on a yearly basis. Hence, we do not require any seasonal adjustment for the income-related and other variables.
} 
examine energy poverty throughout the year. The Appendix also provides the results for winter, for reference. ${ }^{8}$

The second data modification we make is to extend the 2004 data to 2007 -a representative year before the Global Financial Crisis, 2010—a representative year before the GEJE and the incident at Fukushima, and 2013 - a representative and latest year after the GEJE-also with the assistance of the Family Income and Expenditure Survey. This survey includes monthly or annual data on the income and expenditure of Japanese households by income decile group. Hence, we extend the 2004 microdata on household income and expenditure to 2007, 2010 and 2013 such as:

$$
\begin{aligned}
& Y_{i}^{T}=Y_{i}^{0} \times \frac{y_{d}^{T}}{y_{d}^{0}}, \\
& e_{r i}^{T}=e_{r i}^{0} \times \frac{\varepsilon_{r d}^{T}}{\varepsilon_{r d}^{0}} .
\end{aligned}
$$

$Y_{i}^{0}$ is the income of household $i(=\{1, \cdots, 47797\})$ in the base year 2004 in the dataset, $Y_{i}^{T}$ is the income of household $i$ in the terminal year $T(=\{2007,2010$, 2013\}), $y_{d}^{0}$ is the annual average income of households in the $d$-th income decile derived from the Family Income and Expenditure Survey in $2004(d=\{1, \cdots, 10\})$, and $y_{d}^{T}$ in the terminal year T. As in Eq. (3.1), we extend $Y_{i}^{0}$ to $Y_{i}^{T}$ using $y_{d}^{0}$

\footnotetext{
${ }^{8}$ Energy poverty is generally aggravated in winter. For that reason, some researchers feel that energy poverty should be evaluated on the basis of the winter energy expenses (e.g., Moore, 2012).
} 
and $y_{d}^{T}$, the household income in the $d$-th income decile of the Family Income and Expenditure Survey, corresponding to the household i's income decile in the original dataset. In an analogous fashion, we also make $e_{r i}^{T}$, the energy $r$ cost (expenditure) of household $i$ in the terminal year $T$, with $\varepsilon_{r d}^{0}$ and $\varepsilon_{r d}^{T}$ from the Family Income and Expenditure Survey. Here the three types of energy $r$ 'electricity', 'gas', and 'other fuels' (kerosene)- are concerned. This procedure enables us to historically examine the problem of energy poverty in Japan after the 2000s for the first time, fully drawing upon the strength of the original dataset and the subsequent Family Income and Expenditure Surveys.

The microdata comprise a large sample of 47,797 households $(43,861$ two-or-more-person households and 3,936 one-person households) from all of Japan. The household data are fully anonymous and there is no detailed information about the place of residence. Each household has a sampling weight designed to replicate the whole population of Japan. We use these weights in all our calculations to obtain unbiased estimates of the energy poverty rate in Japan.

\section{Results}

We consider energy poverty in Japan during the past few decades and evaluate the factors that drive any changes in energy poverty. We particularly focus on any change in energy poverty in the period before and after 2011, the year of the GEJE and the Fukushima nuclear plant accident. 


\subsection{Overview}

We first summarize Japan’s situation. Fig. 1 depicts the change in domestic energy prices (as measured by the energy consumer price index, the energy CPI) in Japan after the 2000s. ${ }^{9}$ Here, 'energy price’ is a composite index of electricity, gas, and other fuels (kerosene) prices using the 2010 official weights. As shown, the energy price progressively increases after the 2000s in Japan, although we can readily identify a strong increase after 2011. As discussed, almost all nuclear power plants in Japan shut down after 2011 and Japan has become more dependent on fossil fuel imports, a problem compounded by higher international energy prices and a weaker yen after 2011 (see, e.g., METI, 2014b, 2015 for details). Although the energy price has fallen in 2015 reflecting the plunge in international energy prices, it is notable that the price is still higher than the level of 2013.

Fig. 1 Trends in domestic energy price after the 2000s.

\section{[Please insert Fig. 1 here]}

Adding to these difficult conditions, Fig. 2 illustrates that Japan faces a continuous decline in income reflecting Japan’s aging and sluggish economy (see, e.g., MHLW, 2012a, 2012b for details). The figure depicts the gradual decrease in

\footnotetext{
${ }^{9}$ For the change in international energy prices to the latest, see, e.g., Baumeister and Kilian (2016).
} 
household income, as well as a sharp decline after 2008 and the global financial crisis, and a small recovery after 2012.

Fig. 2 Trends in household income after the 2000s.

[Please insert Fig. 2 here]

Using just these aggregate figures, we can well appreciate that energy poverty has been worsening in Japan since the 2000s. ${ }^{10}$ To consider this in more detail, we construct a simple measure using the energy price and household income. This means a kind of 'vulnerability index' for energy poverty. Vulnerability has a wide variety of meanings. In the field of climate change, IPCC (McCarthy et al., 2001) provide a well-known definition of vulnerability: vulnerability is the degree to which a (natural or human) system is susceptible to, or unable to cope with, adverse effects of climate change, and vulnerability is a function of exposure, sensitivity and adaptive capacity. Here, referring to this definition, we construct a simple and convenient 'vulnerability index' for energy poverty; that is, the ratio of the energy CPI to household income, as plotted in Fig. $3 .{ }^{11}$ Here, the change in energy CPI represents the degree of exposure, which drives the increase in energy

${ }^{10}$ Other countries, such as the UK, have faced a similar situation, except for the effect of nuclear shutdown. For example, Boardman (2010) confirms that energy poverty worsened in the UK after 2004 because of the hike in international energy prices.

${ }^{11}$ We also construct another index using the energy expenditure instead of the energy CPI. This modification makes little material difference to the picture of Fig. 3. 
cost, whereas the change in household income reflects the extent of adaptive capacity to manage the increase in energy cost. ${ }^{12}$ The index clearly shows that the level of vulnerability gradually increases, despite minor fluctuations, after the 2000s. It is also noteworthy that there is a sharp upturn in our vulnerability measure after the GEJE, reflecting the dramatic increase in energy prices following the incident at Fukushima. In 2015, the index decreases due to the recent fall in energy prices, though the level of vulnerability is still high, exceeding the level in 2013.

Fig. 3 Vulnerability index for energy poverty after the 2000s.

[Please insert Fig. 3 here]

\subsection{Energy poverty in Japan}

In this subsection, we evaluate energy poverty in Japan in detail using our unique microdata, as an extension of the aggregate analysis in the previous subsection. To measure energy poverty, we employ the approach of energy budget shares discussed earlier. Following the conventional definition, a household is in

${ }^{12}$ In the climate change literature, sensitivity is 'the degree to which a system is affected, either adversely or beneficially, by climate-related stimuli’ (McCarthy et al., 2001, p. 993). However, there is no counterpart to sensitivity in our analysis of energy poverty. Theoretically, elasticities of energy could be a possible candidate for sensitivity. Unfortunately, it is generally difficult to obtain robust estimates of these elasticities (see, e.g., Dawkins et al., 2001). 
energy poverty if it spends over $10 \%$ of its income on energy expenses (costs) (Boardman, 1991, 2010; DECC, 2010; Heindl and Schuessler, 2015; Pachauri et al., 2004; Phimister et al., 2015; Schuessler, 2014). More concretely, our definition (hereafter the $10 \%$ measure) is a variant of the headcount ratio index $P$, in which the terms are the energy cost-income ratios of households $\left(E_{i} / Y_{i}\right)$ and the poverty line $(z)$ equals 0.1 .

$$
P=\frac{Q}{N}=\frac{1}{N} \sum_{i=1}^{N} c\left(\frac{E_{i}}{Y_{i}}>0.1\right)
$$

where $Q=\sum_{i=1}^{N} c\left(\frac{E_{i}}{Y_{i}}>0.1\right)$ is the number of energy-poor households and $N$ is the total number of households. $P$ measures the extent of poverty in the society by the number of the 'poor' $Q$ to the total population $N . c(\cdot)$ is an indicator function that takes a value of one if the condition in brackets is true and zero otherwise. $Y_{i}$ is the income of household $i$; here, income is total (before-tax) income. ${ }^{13,14}$ $E_{i}\left(=\sum_{r} e_{r i}\right)$ is the energy cost (expenditure) of household $i$; the energy cost

13 Our dataset includes only total (before-tax) income for households other than workers' households. These households are quite important in the context of energy poverty. Hence, total income is used for calculation in the analysis. Due to this treatment, the result of the paper might underestimate the situation of energy poverty in Japan. However, there is not so much difference between before- and after-tax incomes especially for the lowest income deciles, which are among the focal points of this study.

${ }^{14}$ In the case of the $10 \%$ measure, income is generally not equivalized because equivalization relates to both energy cost and income. 
includes the three types of energy consumption (in values) for 'electricity', 'gas', and 'other fuels' (kerosene) as explained in the last section. The definition follows Boardman (1991, 2010) and is similar to the UK government measure (DECC, 2010), although it should be noted that energy costs in this paper are actual expenses based on the microdata, rather than the hypothesized values calculated by the model. We measure the energy poverty rates in the year of 2004, 2007, 2010, and 2013, respectively, using the index $P$. It is noteworthy that all the energy poverty rates in the following analysis employ the 'replicating' weights for obtaining unbiased results.

The Hills fuel poverty review identifies some drawbacks associated with this form of the $10 \%$ measure (Hills, 2011, 2012). It is possible that we could mistakenly identify richer households that are merely overconsuming energy goods as energy poor. To overcome this issue, we carefully examine the energy poverty by income decile and only focus on the lower income decile group using this $10 \%$ measure. $^{15}$

We first measure the energy poverty rate in Japan after the 2000s. As shown in Fig. 4, energy poverty rates increase gradually throughout this period, that is, $4.7 \%$ in $2004,6.1 \%$ in $2007,6.8 \%$ in 2010 and $8.4 \%$ in 2013 . There is a sharp increase after the 2011 GEJE, reflecting the escalation of energy prices following the Fukushima incident.

\footnotetext{
15 Heindl and Schuessler (2015) and Schuessler (2014) also recommend applying the 10\% measure to the low-income group only, to avoid this problem.
} 
Fig. 4 Energy poverty rate in Japan.

[Please insert Fig. 4 here]

Fig. 5 illustrates the proportion of energy-poverty households in Japan by income decile group. As shown, the proportion of households experiencing energy poverty in the lowest income decile group steadily increases from 34.6\% in 2004 (the initial year), to $47.5 \%$ in 2013 (the latest year). The proportion of households experiencing energy poverty in the second-to-lowest group also increases from 7.1\% in 2004 to $15.7 \%$ in 2013. In contrast, the rate of energy poverty among households is small in the higher income groups. This suggests that energy price increases over the last decade have mainly aggravated the poverty of lower-income households, especially the lowest income group.

Fig. 5 Energy poverty rate by income decile group.

[Please insert Fig. 5 here]

Fig. 5 also depicts the change in the energy poverty rate in the period before and after 2011, the year of the GEJE and the Fukushima nuclear power plant accident. Even in 2010, the level of energy poverty is high; $42.2 \%$ of households in the lowest income decile and $13.3 \%$ in the second lowest are energy poor. The situation worsens after the GEJE. The shares of energy-poor households escalate to $47.5 \%$ in the lowest and $15.7 \%$ in the second lowest in 2013 . This demonstrates 
the severe impact of the energy price increases after 2011 on lower income households.

Then, this paper attempts to specify the household types who are at high risk of energy poverty (hereafter 'vulnerable households'). ${ }^{16}$ Fig. 6 illustrates the proportion of energy poverty households by household type. The results indicate that mother-child households and single-aged (single-elderly) households are in a serious condition in Japan. Even in 2004-before the rise of international energy prices in the 2000 s, some $16.1 \%$ of mother-child and $14.3 \%$ of single-aged households are in energy poverty. In 2013 (after the GEJE), the energy poverty rate of mother-child households increases to $25 \%$, and that of single-aged households rises to $22.2 \%$. These results show that more than one in seven mother-child and single-aged households are in energy poverty as early as 2004 - even before the Great Surge in international energy prices (Baumeister and Kilian, 2016), and a one-and-a-half times increase between then and 2013. Supplementary evidence also confirms such households' vulnerability in the 2000s. For instance, in the 2007 National Survey on Social Security, 16\% of single-parent-with-dependent-child(ren) households responded that they had experience of failing to pay electricity bills over the past year for economic reasons. $^{17}$

\footnotetext{
${ }^{16}$ Here, the definition of vulnerability is not exactly identical to the one in Subsection 4.1. For the definition of vulnerability in the context of energy poverty, see, e.g., Boardman (2010) or Hills (2012).

${ }^{17}$ Conducted in 2007 by the Ministry of Health, Labour and Welfare, with a gross representative
} 
Fig. 6 Energy poverty rate by household type.

[Please insert Fig. 6 here]

Fig. 6 also shows the change in the rate of energy poverty in the period before and after 2011. Even before the GEJE in 2010, 22.6\% of mother-child and 18.9\% of single-aged households are energy poor, while as many as a quarter of mother-child and single-aged households are experiencing energy poverty in 2013 after the GEJE. This result evidences that the energy price hikes after 2011 stifled the livelihoods of low-income and vulnerable households especially.

\subsection{Decomposition analysis}

The analysis in this paper clearly illustrates a continuous increase in energy poverty rates in Japan between 2004 and 2013. In this subsection, we attempt to identify the factors that drove the changes in energy poverty in Japan using a new approach to the decomposition of poverty indices, being a simple decomposition using the Shapley decomposition technique, as developed by Shorrocks (2013). The Shapley decomposition yields an exact (complete) decomposition and produces no residual terms, unlike conventional decomposition procedures with significant residuals. ${ }^{18}$ Without residual or interaction terms, the Shapley technique can totally and comprehensively disentangle the change in energy poverty rates into the contributions of the several explanatory factors.

sample of 15,782 households from the whole of Japan and a response rate of $68.2 \%$.

${ }^{18}$ For conventional decomposition procedures, see, e.g., Okushima and Tamura $(2007,2011)$. 
Assume an index $I$ whose value is determined by a set of $m$ factors, $X_{k}$

$(k=1,2, \cdots, m)$ :

$$
I=f\left(X_{1}, X_{2}, \cdots, X_{m}\right),
$$

where $f()$ is the underlying functional relationship. In the context of energy poverty, the important factors fall into two categories: energy cost and income. ${ }^{19}$ As an index for measuring energy poverty, we use:

$$
P=f(\mathbf{E}, \mathbf{Y}, z),
$$

where $P$ is an energy poverty index (the $10 \%$ measure in this paper), $\mathbf{E}$ is energy cost, $\mathbf{Y}$ is income, and $z$ is the poverty threshold. In the $10 \%$ measure case, $z$ is constant at 0.1 ; therefore, we need not consider this further for decomposition.

We apply the Shapley decomposition to the change in the energy poverty index, i.e., the $10 \%$ measure, and exactly decompose the additive change in the energy poverty index between the initial $(t-1)$ and terminal $(t)$ periods using:

$$
\begin{gathered}
P\left(\mathbf{E}^{t}, \mathbf{Y}^{t}, \bar{z}\right)-P\left(\mathbf{E}^{t-1}, \mathbf{Y}^{t-1}, \bar{z}\right) \\
=\frac{1}{2}\left(\left(P\left(\mathbf{E}^{t}, \mathbf{Y}^{t}, \bar{z}\right)-P\left(\mathbf{E}^{t-1}, \mathbf{Y}^{t}, \bar{z}\right)\right)+\left(P\left(\mathbf{E}^{t}, \mathbf{Y}^{t-1}, \bar{z}\right)-P\left(\mathbf{E}^{t-1}, \mathbf{Y}^{t-1}, \bar{z}\right)\right)\right)
\end{gathered}
$$

(Contribution of 'energy cost')

$$
+\frac{1}{2}\left(\left(P\left(\mathbf{E}^{t}, \mathbf{Y}^{t}, \bar{z}\right)-P\left(\mathbf{E}^{t}, \mathbf{Y}^{t-1}, \bar{z}\right)\right)+\left(P\left(\mathbf{E}^{t-1}, \mathbf{Y}^{t}, \bar{z}\right)-P\left(\mathbf{E}^{t-1}, \mathbf{Y}^{t-1}, \bar{z}\right)\right)\right)
$$

(Contribution of 'income')

\footnotetext{
19 For example, Boardman (1991, 2010) and Hills (2011, 2012) emphasize energy prices (energy costs) and low income as the main drivers of energy poverty.
} 
As shown in the equation, the Shapley decomposition regards the contribution of each explanatory factor as the average of $m$ ! estimated contributions over all the possible elimination sequences (see Shorrocks (2013) for details). Here, the Shapley technique quantifies the contribution of 'energy cost' as the average impact of the change in energy cost from the initial to the terminal period (from $\mathbf{E}^{\mathrm{t}-1}$ to $\mathbf{E}^{\mathrm{t}}$ ) using the initial $\mathbf{Y}^{\mathrm{t}-1}$ and terminal $\mathbf{Y}^{\mathrm{t}}$ period weights, and the contribution of 'income' as the average impact of the income change from $\mathbf{Y}^{\mathrm{t}-1}$ to $\mathbf{Y}^{\mathrm{t}}$ using the $\mathbf{E}^{\mathrm{t}-1}$ and $\mathbf{E}^{\mathrm{t}}$ weights.

In the equation, the left-hand side of the equality is the additive change in the energy poverty index between the initial and terminal periods using the $10 \%$ measure. The first half of the right-hand side of the equality is the contribution of energy cost to the change in energy poverty rates between the periods, whereas the second half is the contribution of income. Therefore, the Shapley technique perfectly decomposes the change in energy poverty into two parts: one part attributable to energy costs and the other part attributable to income.

We further decompose the change in the energy poverty rates between the periods 2004, 2010, and 2013, and focus on the changes for the lower-income deciles and vulnerable households (mother-child and single-aged). Table 1 provides the decomposition results. As shown, both energy cost and income positively contribute to the increase in energy poverty from 2004 to 2010; the period before the GEJE. It is notable that the contribution of lowering income stands out, rather than that of energy cost hike. On the other hand, from 2010 to 
2013, immediately before and after the GEJE, income becomes the alleviating factor and energy cost is the principal factor driving the increase in energy poverty. After the Fukushima accident, the increase of energy cost becomes the primary driving force of energy poverty in Japan. The results clearly show there were major changes in these driving factors before and after the GEJE and the Fukushima nuclear power plant accident.

Table 1 Decomposition of the change in the energy poverty index.

\section{[Please insert Table 1 here]}

\subsection{Energy efficiency}

Finally, we consider the impact of energy efficiency improvement on energy poverty. Energy efficiency improvements, e.g., by energy-saving investments, would generally cause lower energy costs of households, which reduces energy poverty (Hills, 2012). ${ }^{20}$ Notably, the contribution of energy cost in the above decomposition analysis includes that effect of energy efficiency. Nonetheless, it is considered that households in energy poverty can little afford to make energy-saving investments on their own and can benefit little from the effect of energy efficiency improvements (Boardman, 2010).

In the context of energy poverty, previous studies yield ample evidence of the importance of energy efficiency of housing (e.g., Boardman, 1991, 2010; Hills,

\footnotetext{
${ }^{20}$ Precisely, we need to consider the rebound effect, although it is said that the size of the rebound is not large for residential end uses (Greening et al., 2000).
} 
2012). For example, Boardman (2010) shows that energy-poor households usually live in old, energy-inefficient homes. Even in our data, Fig. 7 describes large shares of energy-poor households living in old homes that were built before 1979. ${ }^{21}$ After the oil shocks in the 1970s, the Japanese government established the energy conservation standards for housing in 1980 for the first time. Regarding thermal insulation, energy efficiency improves by 30\% before and after the 1980 standard (METI, 2011). Against this backgrounds, it is of primary importance to strengthen measures for promoting energy-saving investments specifically targeting energy-poor households (see, e.g., Boardman, 2010; Brunner et al., 2012).

Fig. 7 Housing conditions of energy-poor households.

[Please insert Fig. 7 here]

\section{Conclusion and policy implications}

This paper evaluates the past and present situation concerning energy poverty in Japan, and identifies the factors accounting for changes in energy poverty after the 2000s. The results show that energy poverty has worsened in Japan, especially for lower-income households and vulnerable households (mother-child and single-aged households) after the 2000s. It also explains, using the Shapley

21 The lifespan of housing is said to be about 27 years in Japan (e.g., Ministry of the Environment, 2014). Due to the data limitations, we can only check the age of owned houses. 
decomposition, that both income and energy cost are positive factors in worsening energy poverty before 2011, whereas after 2011, the contribution of income moderates any increase in poverty rates, and so energy cost remains the sole factor driving the increase in energy poverty after the Fukushima nuclear plant accident.

Of late, we could expect that the downturn in international energy prices could ease energy poverty in Japan to some extent. Restarting some nuclear power plants after 2015 could also help push electricity prices down. These might alleviate the difficulties of lower-income and vulnerable households regarding energy costs. However, the persistent sluggish economy, the substantially continuing nuclear power plant shutdown, the possible upturn of international energy prices, the weaker yen, and the need for higher carbon pricing to meet the Paris agreement's target, etc., offset such straightforward optimism (see, e.g., Suzuki et al., 2016). Furthermore, there is a rising chorus of concern about the FIT scheme in Japan; for example, METI (2016) estimates the burden placed by FIT on the population to amount to 1.8 trillion yen in the fiscal year 2016. This echoes the result of this paper, i.e., that more than one in seven vulnerable households were energy poor in Japan even in 2004_-before the Great Surge in international energy prices.

Considering such a background, in some cases, the government may need to consider countermeasures to address energy poverty, such as social tariffs, from the perspective of poverty and redistribution. ${ }^{22}$ Above all, the government should

\footnotetext{
${ }^{22}$ Introduced in the UK from 2008 to 2011, social tariffs were often the subject of criticism. One
} 
introduce effective measures for promoting energy-saving investments, especially for housing, that particularly target low-income and vulnerable households (see, e.g., Boardman, 2010; Brunner et al., 2012).

Additional research is necessary, especially on the definition of energy poverty. Going back to the root of the definition, Boardman (1991) focuses on three factors — energy price, low income, and energy efficiency (of the house) —in considering energy poverty in developed countries. Hills (2011, 2012) also stresses fuel prices, low income, and energy efficiency as the three main drivers of energy poverty. These seminal studies show that the nature of energy poverty is a kind of multidimensional poverty. With this in mind, we need to reconsider the measurement of energy poverty from a multidimensional poverty viewpoint other than a unidimensional one (see, e.g., Kakwani and Silber, 2007).

This paper empirically presents the situation of energy poverty in Japan after the 2000s for the first time. We trust that the findings will produce important implications for future practices in tackling the problem of energy poverty in Japan and in other developed countries.

problem is that the tariffs were offered by energy utilities, not the government, and their costs financed by energy bills, with the recent literature recommending costs be borne by taxes (e.g., Boardman, 2010; Chawla and Pollitt, 2013). 


\section{Acknowledgments}

Preliminary versions of this paper were presented at conferences of the International Association for Energy Economics. The author would like to thank his colleagues, students and the staff of the National Statistics Center for their assistance with this research, and also wishes to thank the editor and anonymous referees of this journal. This research was supported by the Grant-in-Aid for Scientific Research (JSPS KAKENHI Grant No. 23710052) and the Grant for Environmental Research Projects from the Sumitomo Foundation. 


\section{Appendix: Seasonality}

This Appendix illustrates the energy poverty rates in three cases of different seasonal adjustment. The first case is no seasonal adjustment (the original figures, being the average from September to November); the second is the case of seasonal adjustment to the annual average (the average from January to December) — the main result in this study; the third is of seasonal adjustment to the winter average (the average from January to March). ${ }^{23}$ This result illustrates the robustness of the implication of this paper to the seasonal-adjustment procedure, which we generally confirm. However, the result indicates the energy poverty rates in winter are quite high. It points out that we need to pay more attention when we evaluate the levels of figures that have a marked seasonality factor, such as energy poverty.

Table A.1 Trends in energy poverty rates in Japan.

[Please insert Table A.1 here]

${ }^{23}$ Winter in Japan is December, January, and February. However, fuel bills usually lag usage by a month, so January to March are the peak fuel billing periods during the year in Japan. 


\section{References}

Atkinson, A.B. (2003), “Multidimensional Deprivation: Contrasting Social Welfare and Counting Approaches,” Journal of Economic Inequality, 1, pp. $51-65$.

Baumeister, C. and Kilian, L. (2016), “Forty Years of Oil Price Fluctuations: Why the Price of Oil May Still Surprise Us,” Journal of Economic Perspectives, 30(1), pp. 139-160.

Boardman, B. (1991), Fuel Poverty: From Cold Homes to Affordable Warmth. Belhaven Press, London.

Boardman, B. (2010), Fixing Fuel Poverty: Challenges and Solutions. Earthscan, London.

Bourguignon, F. and Chakravarty, S.R. (2003), “The Measurement of Multidimensional Poverty,” Journal of Economic Inequality, 1, pp. 25-49.

Bouzarovski, S., Petrova, S., and Sarlamanov, R. (2012), “Energy Poverty Policies in the EU: A Critical Perspective,” Energy Policy, 49, pp.76-82.

Brunner, K.-M., Spitzer, M., Christanell, A. (2012), “Experiencing Fuel Poverty. Coping Strategies of Low-income Households in Vienna/Austria,” Energy Policy, 49, pp. 53-59.

Chawla, M. and Pollitt, M.G. (2013), “Energy-efficiency and Environmental Policies and Income Supplements in the UK: Evolution and Distributional Impacts on Domestic Energy Bills,” Economics of Energy and Environmental 
Policy, 2(1), pp. 21-40.

Dawkins, C., Srinivasan, T.N., Whalley, J. (2001), “Calibration.” In: Heckman, J.J., Leamer, E. (Eds.), Handbook of Econometrics, vol. 5. Elsevier, New York, pp. 3653-3703.

DECC (Department of Energy and Climate Change) (2010), Fuel Poverty Methodology Handbook. Department of Energy and Climate Change, Government of UK, London.

Greening, L.A., Greene, D.L., Difiglio, C. (2000), “Energy Efficiency and Consumption - the Rebound Effect - A Survey,” Energy Policy, 28, pp. $389-401$

Greer, J. and Thorbecke, E. (1986), “A Methodology for Measuring Food Poverty Applied to Kenya,” Journal of Development Economics, 24, pp. 59-74.

Haughton, J. and Khandker, S.R. (2009), Handbook on Poverty and Inequality. World Bank, Washington, DC.

Heindl, P. and Schuessler, R. (2015), “Dynamic Properties of Energy Affordability Measures,” Energy Policy, 86, pp. 123-132.

Hills, J. (2011), Fuel Poverty: The Problem and its Measurement. Department of Energy and Climate Change, Government of UK, London.

Hills, J. (2012), Getting the Measure of Fuel Poverty. Department of Energy and Climate Change, Government of UK, London.

IEA (International Energy Agency) (2010), Energy Poverty: How to Make Modern Energy Access Universal? OECD/IEA, Paris.

Kakwani, N. and Silber, J. (Eds.) (2007), The Many Dimensions of Poverty. 
Palgrave Macmillan, New York.

Li, K., Lloyd, B., Liang, X., and Wei, Y. (2014), “Energy Poor or Fuel Poor: What Are the Differences?” Energy Policy, 68, pp. 476-481.

McCarthy, J.J., Canziani, O.F., Leary, N.A., Dokken, D.J., and White, K.S. (2001) Climate Change 2001: Impacts, Adaptation, and Vulnerability: Contribution of Working Group II to the Third Assessment Report of the Intergovernmental Panel on Climate Change. Cambridge University Press, Cambridge, UK. METI (Ministry of Economy, Trade and Industry) (2011), Energy Conservation Policies of Japan. Ministry of Economy, Trade and Industry, Government of Japan, Tokyo.

METI (Ministry of Economy, Trade and Industry) (2014a), Strategic Energy Plan. Ministry of Economy, Trade and Industry, Government of Japan, Tokyo. METI (Ministry of Economy, Trade and Industry) (2014b), Energy White Paper 2014. Ministry of Economy, Trade and Industry, Government of Japan, Tokyo. METI (Ministry of Economy, Trade and Industry) (2015), Energy White Paper 2015. Ministry of Economy, Trade and Industry, Government of Japan, Tokyo. METI (Ministry of Economy, Trade and Industry) (2016), Energy White Paper 2016. Ministry of Economy, Trade and Industry, Government of Japan, Tokyo. MHLW (Ministry of Health, Labour and Welfare) (2012a), White Paper on Annual Health, Labour and Welfare 2012. Ministry of Health, Labour and Welfare, Government of Japan, Tokyo.

MHLW (Ministry of Health, Labour and Welfare) (2012b), White Paper on Labour and Economy 2012. Ministry of Health, Labour and Welfare, 
Government of Japan, Tokyo.

Ministry of the Environment (2014), Annual Report on the Environment, the Sound Material-Cycle Society, and Biodiversity in Japan 2014. Ministry of the Environment, Government of Japan, Tokyo.

Moore, R. (2012), “Definitions of Fuel Poverty: Implications for Policy,” Energy Policy, 49, pp. 19-26.

Okushima, S. and Tamura, M. (2007), “Multiple Calibration Decomposition Analysis: Energy Use and Carbon Dioxide Emissions in the Japanese Economy, 1970-1995,” Energy Policy, 35, pp. 5156-5170.

Okushima, S. and Tamura, M. (2011), “Identifying the Sources of Energy Use Change: Multiple Calibration Decomposition Analysis and Structural Decomposition Analysis,” Structural Change and Economic Dynamics, 22, pp. 313-326.

Pachauri, S., Mueller, A., Kemmler, A., and Spreng, D. (2004), “On Measuring Energy Poverty in Indian Households,” World Development, 32(12), pp. 2083-2104.

Phimister, E., Vera-Toscano, E., and Roberts, D. (2015), “The Dynamics of Energy Poverty: Evidence from Spain,” Economics of Energy and Environmental Policy, 4(1), pp. 153-166.

Schuessler, R. (2014), “Energy Poverty Indicators: Conceptual Issues: Part I: The Ten-Percent-Rule and Double Median/Mean Indicators,” ZEW Discussion Paper, No. 14-037.

Sen, A. (1976), “Poverty: An Ordinal Approach to Measurement,” Econometrica, 
44(2), pp. 219-231.

Sen, A. (1979), “Issues in the Measurement of Poverty,” Scandinavian Journal of Economics, 81(2), pp. 285-307.

Sen, A. (1997), On Economic Inequality: Enlarged Edition. Clarendon Press, Oxford.

Shorrocks, A.F. (2013), “Decomposition Procedures for Distributional Analysis: A Unified Framework Based on the Shapley Value,” Journal of Economic Inequality, 11, pp. 99-126.

Suzuki, T., Kobayashi, T., Kobayashi, H., and Iwata, K. (2016), “Aiming at a Low Carbon Society in Japan by 2050: Impact of the Fukushima Nuclear Accident and $\mathrm{CO}_{2}$ Reduction Target," Economics of Energy and Environmental Policy, 5(1), pp. 89-103.

Thomson, H. and Snell, C. (2013), “Quantifying the Prevalence of Fuel Poverty across the European Union,” Energy Policy, 52, pp. 563-572.

Tobin, J. (1970), “On Limiting the Domain of Inequality,” Journal of Law and Economics, 13(2), pp. 263-277.

Waddams Price, C., Brazier, K., and Wang, W. (2012), “Objective and Subjective Measures of Fuel Poverty,” Energy Policy, 49, pp. 33-39. 
Table 1

Decomposition of the change in the energy poverty index.

\begin{tabular}{|c|c|c|c|c|}
\hline & & $2004-2013$ & $2004-2010$ & $2010-2013$ \\
\hline \multicolumn{5}{|c|}{ Whole population } \\
\hline & Change in energy poverty rate & $3.7 \%$ & $2.1 \%$ & $1.6 \%$ \\
\hline & Contribution of energy cost & $2.7 \%$ & $0.9 \%$ & $1.9 \%$ \\
\hline & Contribution of income & $0.9 \%$ & $1.2 \%$ & $-0.4 \%$ \\
\hline \multicolumn{5}{|c|}{ - $\quad$ Lowest income decile group } \\
\hline & Change in energy poverty rate & $12.8 \%$ & $7.5 \%$ & $5.3 \%$ \\
\hline & Contribution of energy cost & $11.2 \%$ & $2.5 \%$ & $9.2 \%$ \\
\hline & Contribution of income & $1.6 \%$ & $5.0 \%$ & $-3.9 \%$ \\
\hline \multicolumn{5}{|c|}{ - $\quad$ Second lowest income decile group } \\
\hline & Change in energy poverty rate & $8.6 \%$ & $6.2 \%$ & $2.4 \%$ \\
\hline & Contribution of energy cost & $5.8 \%$ & $2.5 \%$ & $3.1 \%$ \\
\hline & Contribution of income & $2.8 \%$ & $3.7 \%$ & $-0.7 \%$ \\
\hline \multicolumn{5}{|c|}{ - $\quad$ Mother-child } \\
\hline & Change in energy poverty rate & $8.9 \%$ & $6.5 \%$ & $2.4 \%$ \\
\hline & Contribution of energy cost & $6.5 \%$ & $2.7 \%$ & $3.6 \%$ \\
\hline & Contribution of income & $2.4 \%$ & $3.9 \%$ & $-1.2 \%$ \\
\hline \multicolumn{5}{|c|}{ - $\quad$ Single-aged } \\
\hline & Change in energy poverty rate & $7.9 \%$ & $4.6 \%$ & $3.4 \%$ \\
\hline & Contribution of energy cost & $6.8 \%$ & $1.9 \%$ & $5.4 \%$ \\
\hline & Contribution of income & $1.1 \%$ & $2.7 \%$ & $-2.0 \%$ \\
\hline
\end{tabular}


Table A.1

Trends in energy poverty rates in Japan.

\begin{tabular}{|c|c|c|c|c|c|c|c|c|c|c|c|c|c|}
\hline & & \multicolumn{4}{|c|}{ No seasonal adjustment } & \multicolumn{4}{|c|}{$\begin{array}{l}\text { Seasonal adjustment to } \\
\text { the annual average }\end{array}$} & \multicolumn{4}{|c|}{$\begin{array}{l}\text { Seasonal adjustment to } \\
\text { the winter average }\end{array}$} \\
\hline & & 2004 & 2007 & 2010 & 2013 & 2004 & 2007 & 2010 & 2013 & 2004 & 2007 & 2010 & 2013 \\
\hline Energy poverty rate & & $3.2 \%$ & $4.1 \%$ & $4.6 \%$ & $5.8 \%$ & $4.7 \%$ & $6.1 \%$ & $6.8 \%$ & $8.4 \%$ & $8.6 \%$ & $11.5 \%$ & $12.7 \%$ & $15.2 \%$ \\
\hline Income decile & I & $25.8 \%$ & $31.5 \%$ & $32.5 \%$ & $38.4 \%$ & $34.6 \%$ & $40.8 \%$ & $42.2 \%$ & $47.5 \%$ & $50.0 \%$ & $57.1 \%$ & $58.7 \%$ & $63.3 \%$ \\
\hline & II & $4.1 \%$ & $5.8 \%$ & $7.6 \%$ & $9.4 \%$ & $7.1 \%$ & $10.0 \%$ & $13.3 \%$ & $15.7 \%$ & $17.0 \%$ & $22.0 \%$ & $26.4 \%$ & $29.4 \%$ \\
\hline & III & $1.3 \%$ & $2.4 \%$ & $3.5 \%$ & $5.6 \%$ & $3.1 \%$ & $5.6 \%$ & $7.0 \%$ & $9.9 \%$ & $9.2 \%$ & $14.5 \%$ & $17.3 \%$ & $22.3 \%$ \\
\hline & IV & $0.3 \%$ & $0.8 \%$ & $1.3 \%$ & $2.0 \%$ & $1.3 \%$ & $2.0 \%$ & $2.8 \%$ & $4.4 \%$ & $4.4 \%$ & $7.6 \%$ & $9.9 \%$ & $13.4 \%$ \\
\hline & $\mathrm{V}$ & $0.2 \%$ & $0.5 \%$ & $0.6 \%$ & $1.4 \%$ & $0.5 \%$ & $1.4 \%$ & $1.6 \%$ & $3.6 \%$ & $2.6 \%$ & $5.8 \%$ & $6.4 \%$ & $10.7 \%$ \\
\hline & VI & $0.1 \%$ & $0.1 \%$ & $0.2 \%$ & $0.5 \%$ & $0.2 \%$ & $0.6 \%$ & $0.7 \%$ & $1.5 \%$ & $1.3 \%$ & $3.6 \%$ & $3.9 \%$ & $6.5 \%$ \\
\hline & VII & $0.0 \%$ & $0.1 \%$ & $0.1 \%$ & $0.1 \%$ & $0.1 \%$ & $0.2 \%$ & $0.2 \%$ & $0.5 \%$ & $0.7 \%$ & $1.8 \%$ & $2.0 \%$ & $3.1 \%$ \\
\hline & VIII & $0.0 \%$ & $0.0 \%$ & $0.0 \%$ & $0.1 \%$ & $0.1 \%$ & $0.2 \%$ & $0.2 \%$ & $0.4 \%$ & $0.5 \%$ & $1.3 \%$ & $1.2 \%$ & $2.0 \%$ \\
\hline & IX & $0.0 \%$ & $0.0 \%$ & $0.0 \%$ & $0.0 \%$ & $0.0 \%$ & $0.0 \%$ & $0.0 \%$ & $0.1 \%$ & $0.1 \%$ & $0.5 \%$ & $0.5 \%$ & $0.8 \%$ \\
\hline & $\mathrm{X}$ & $0.0 \%$ & $0.0 \%$ & $0.0 \%$ & $0.0 \%$ & $0.0 \%$ & $0.0 \%$ & $0.0 \%$ & $0.0 \%$ & $0.1 \%$ & $0.2 \%$ & $0.1 \%$ & $0.1 \%$ \\
\hline Mother-ch & & $10.7 \%$ & $13.9 \%$ & $14.7 \%$ & $17.4 \%$ & $16.1 \%$ & $20.5 \%$ & $22.6 \%$ & $25.0 \%$ & $26.0 \%$ & $29.8 \%$ & $31.7 \%$ & $34.4 \%$ \\
\hline Single-ą & & $10.2 \%$ & $13.2 \%$ & $13.8 \%$ & $17.1 \%$ & $14.3 \%$ & $17.6 \%$ & $18.9 \%$ & $22.2 \%$ & $23.2 \%$ & $29.0 \%$ & $31.3 \%$ & $35.7 \%$ \\
\hline & sed & $3.0 \%$ & $4.5 \%$ & $5.1 \%$ & $6.7 \%$ & $5.1 \%$ & $7.3 \%$ & $8.4 \%$ & $11.0 \%$ & $11.0 \%$ & $16.2 \%$ & $18.5 \%$ & $22.9 \%$ \\
\hline Single-pers & on & $3.4 \%$ & $4.1 \%$ & $4.5 \%$ & $5.5 \%$ & $4.8 \%$ & $5.9 \%$ & $6.5 \%$ & $7.3 \%$ & $8.1 \%$ & $9.7 \%$ & $10.4 \%$ & $11.7 \%$ \\
\hline & her & $1.9 \%$ & $2.4 \%$ & $2.8 \%$ & $3.6 \%$ & $2.8 \%$ & $3.8 \%$ & $4.4 \%$ & $5.7 \%$ & $5.7 \%$ & $8.1 \%$ & $9.1 \%$ & $11.4 \%$ \\
\hline
\end{tabular}

Note: All figures estimated with replicating weights. 
Fig. 1 Trends in domestic energy price after the 2000s.

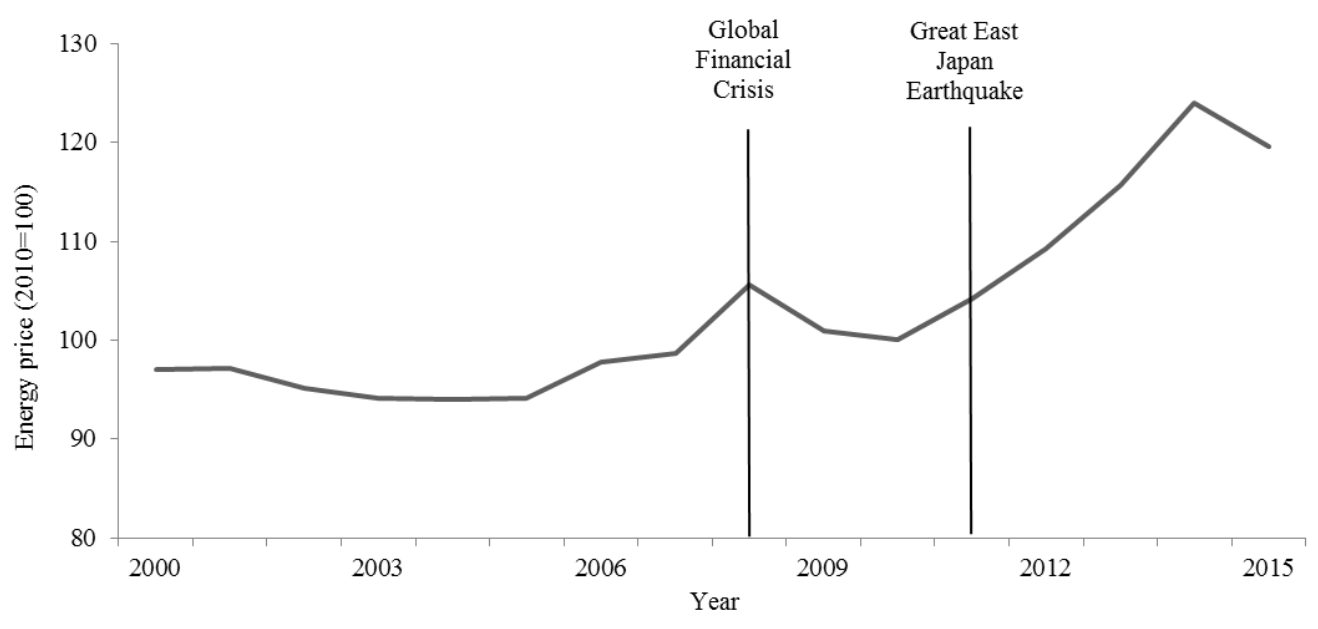

Note: 'Energy price' is a composite index of electricity, gas, and other fuels with the weights in 2010. All figures are CPIs (consumer price index) by Statistics Bureau, Ministry of Internal Affairs and Communications, Japan. 
Fig. 2 Trends in household income after the 2000s.

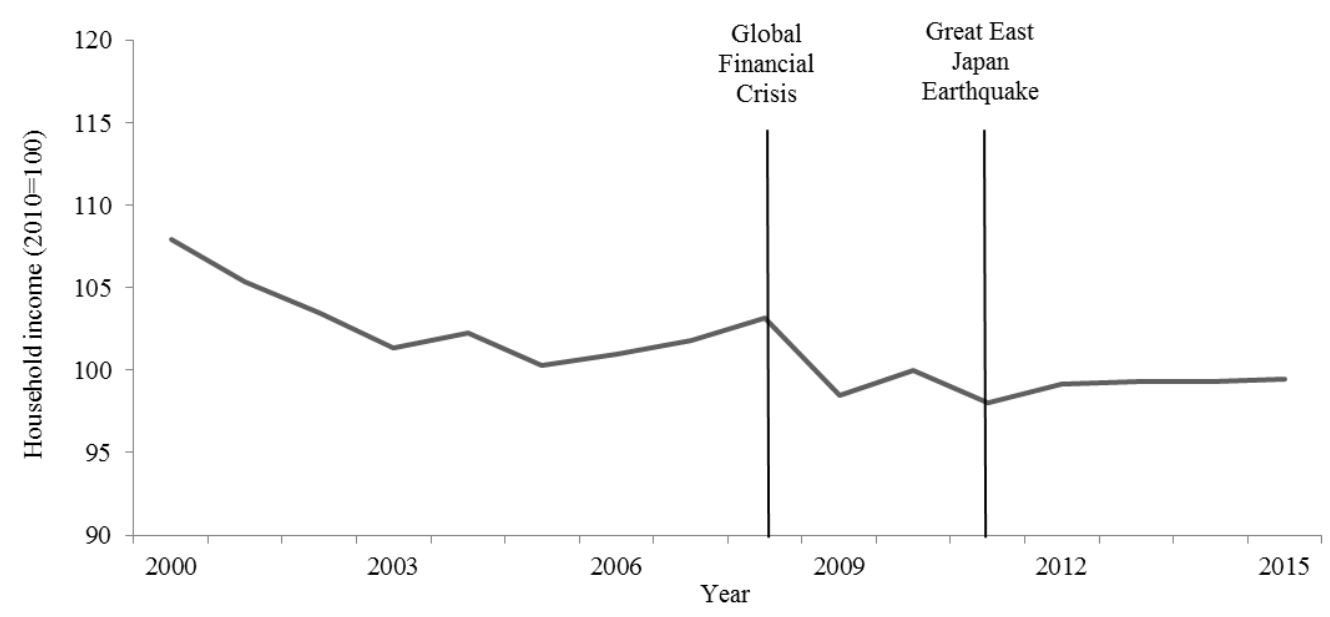

Note: Annual average income of all workers' households derived from the Family Income and Expenditure Survey,

Statistics Bureau, Ministry of Internal Affairs and Communications, Japan. 
Fig. 3 Vulnerability index for energy poverty after the 2000s.

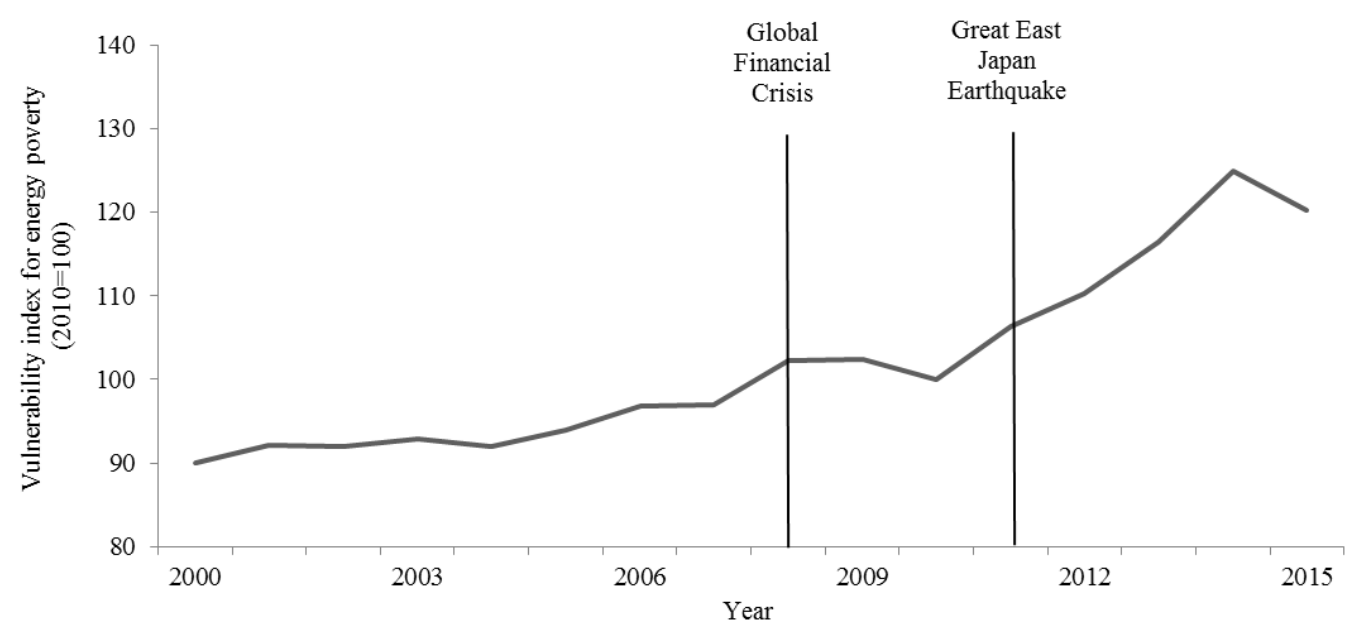


Fig. 4 Energy poverty rate in Japan.

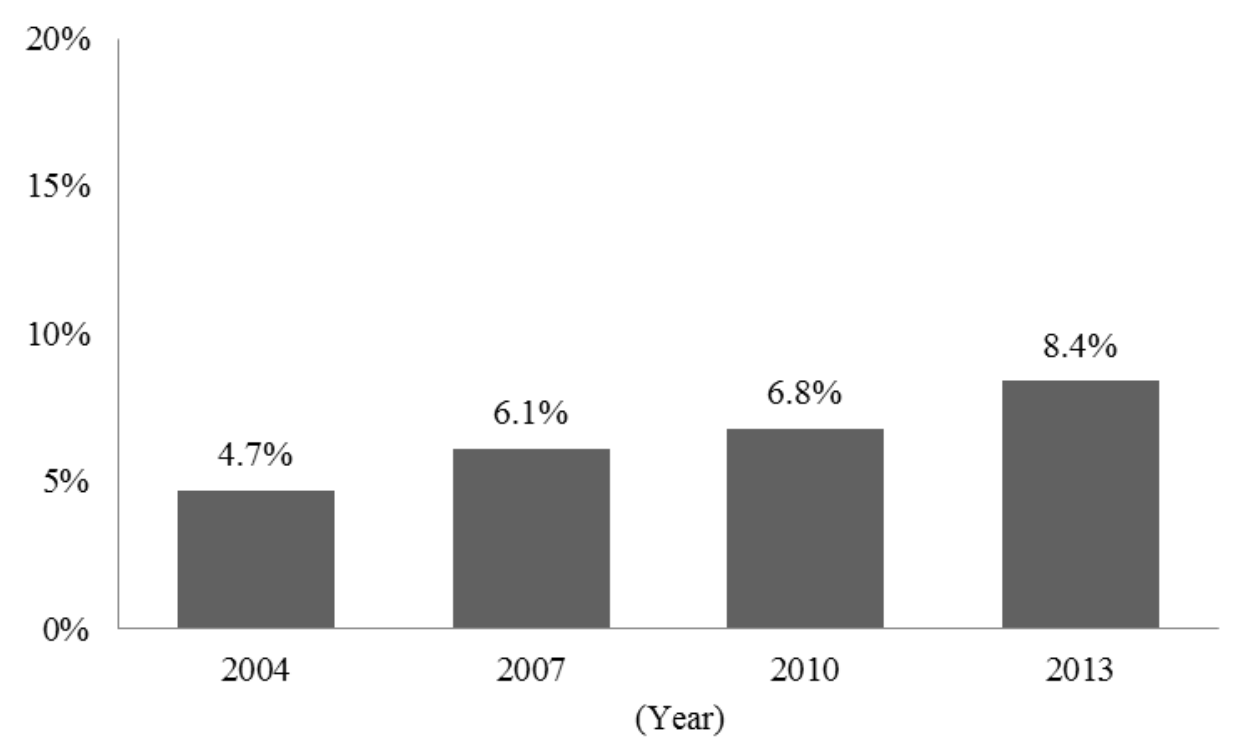


Fig. 5 Energy poverty rate by income decile group.

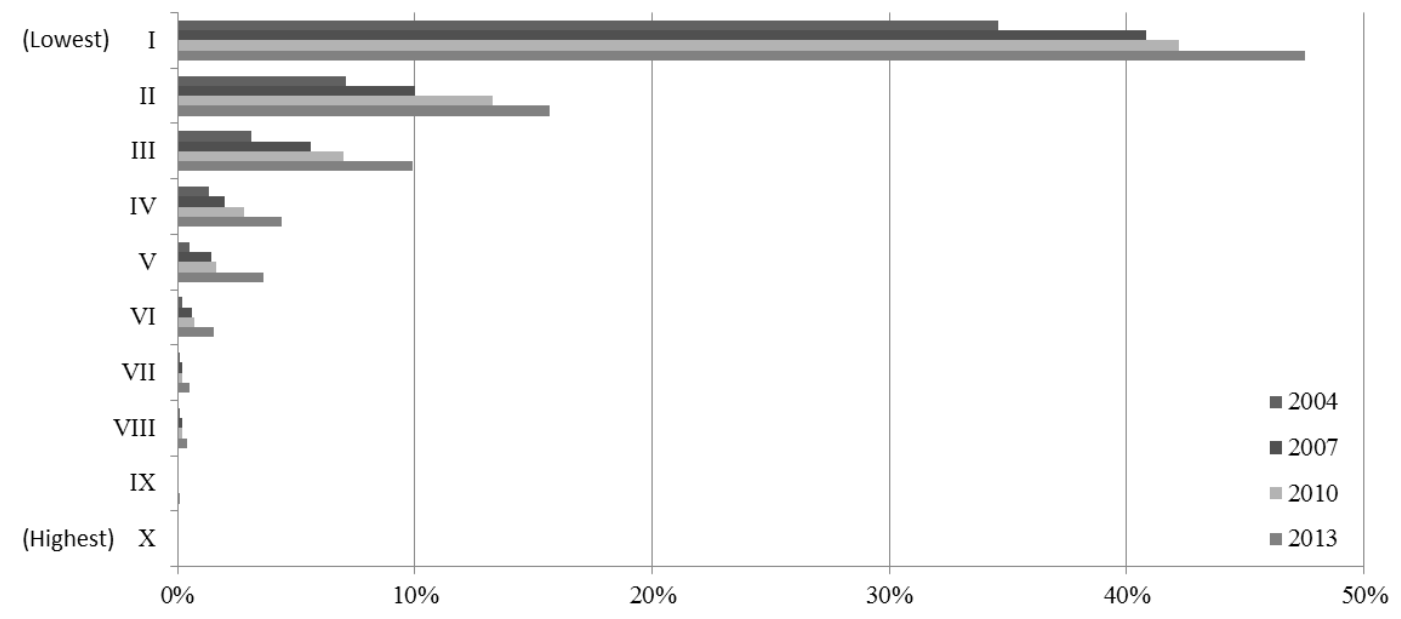


Fig. 6 Energy poverty rate by household type.

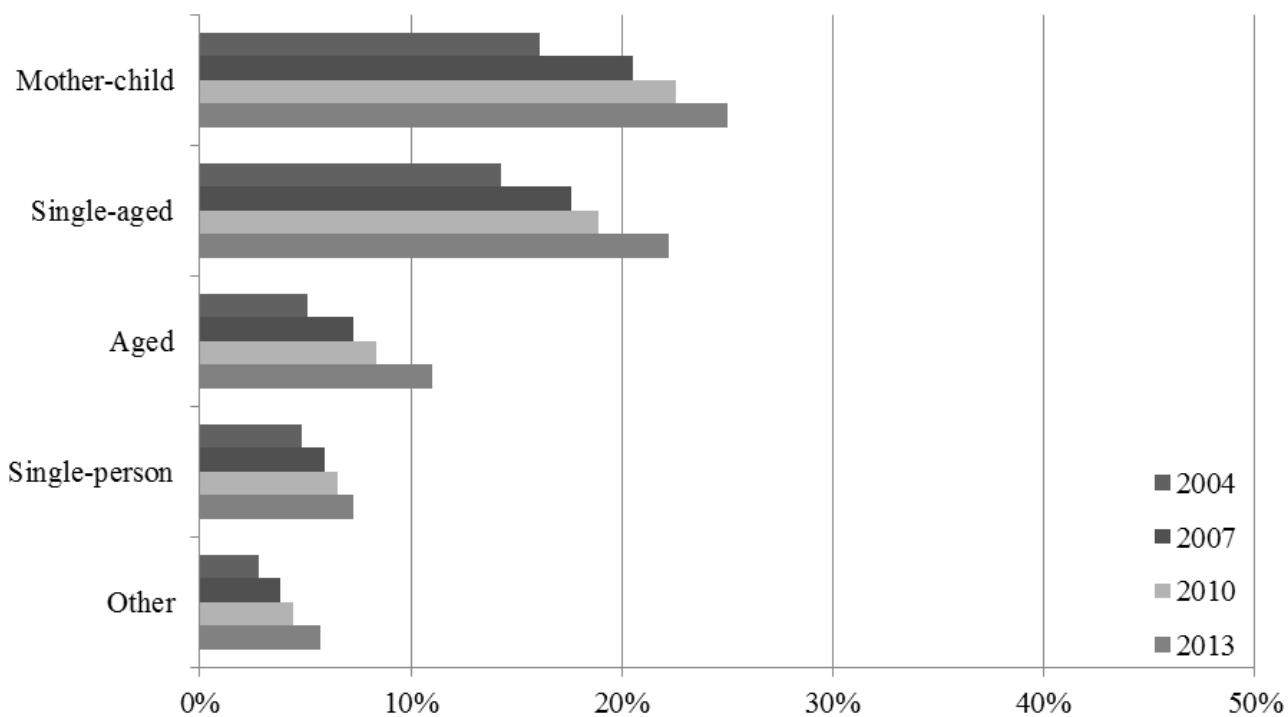

Note: Mother-child households are composed of a single female parent and an unmarried child (or children). Single-aged households comprise a single person 65 years of age or over. Aged households are households with two or more persons 65 years of age or over. Single-person households comprise a single person under 65 years of age. 
Fig. 7 Housing conditions of energy-poor households.

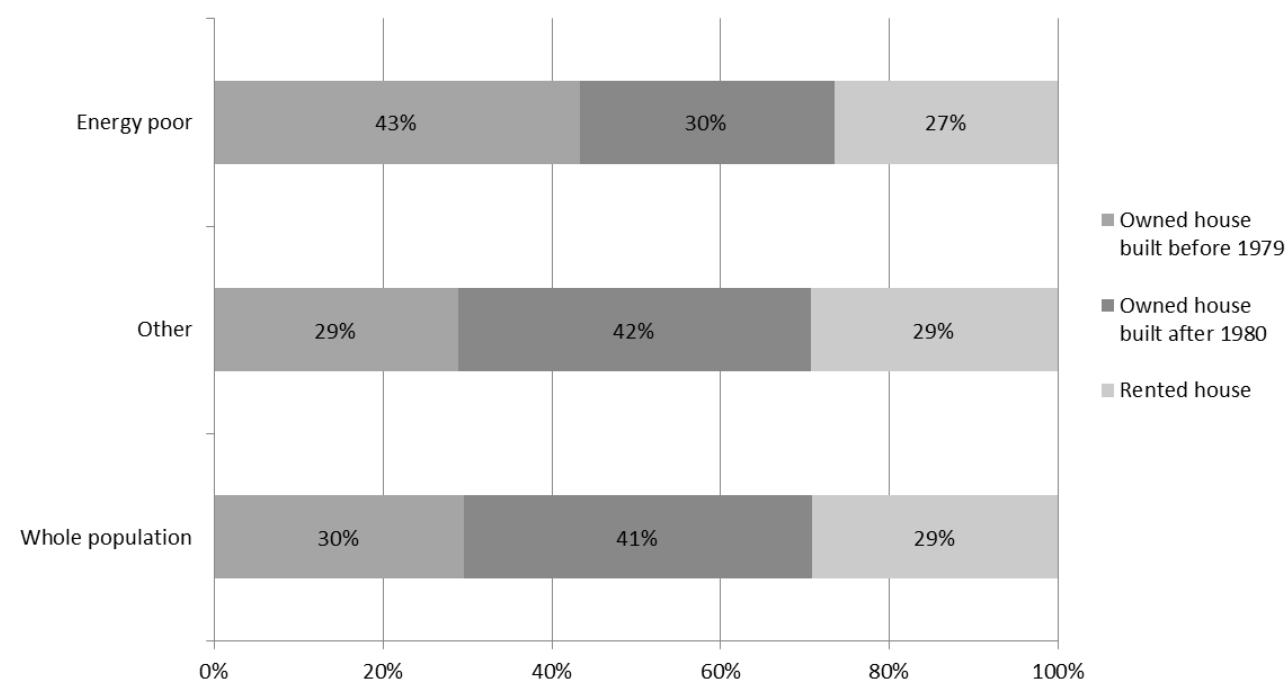

Note: 'Energy poor' are the households in energy poverty in 2004. 'Other' are the households not in energy poverty. 